\title{
The facilitating effects of prior inescapable/unavoidable stress on intellectual performance*
}

\author{
JERRY W. THORNTON, Angelo State University, San Angelo, Tex. 76901 \\ and \\ PAUL D. JACOBS $\uparrow$, University of Oklahoma, Norman, Okla. 73069
}

Two experiments were performed to test the effect of prior inescapable/unavoidable shock on subsequent intellectual performance. Both experiments revealed that prior experience with inescapable/unavoidable stress significantly increased posttest intelligence measures as compared to groups who were given either prior trials of avoidable stress or no stress. The learned helplessness hypothesis, in addition to several alternative hypotheses, was considered in an attempt to interpret the results theoretically.

The effects of prior inescapable shock on later test trials of escape/avoidance responding have been reviewed most recently by Seligman, Maier, \& Solomon (1969). Overmier \& Seligman (1967) and Seligman \& Maier (1967) reported that harnessed dogs who received training trials of yoked inescapable shock followed by test trials of escape/avoidance shuttling in a two-way shuttlebox were severely retarded in their performance as compared to a group that received initial trials of escapable shock. Seligman et al (1969) have theorized that $\mathbf{S}$ learns an independence between responding and reinforcement. The phenomenon, labeled "learned helplessness," is manifest in terms of interference built up in the inescapable preshock group which transfers from one task to another.

Seligman et al (1969) discuss four points regarding the relation of independence between responses and shocks and the consequent interference phenomenon. First, $\mathbf{S}$ makes active responses to inescapable stress. Second, since stress is uncontrollable, $\mathrm{S}$ learns that shock termination is independent of his responses. Third, S's incentive for initiating active responses during shock is assumed to be produced in part by the expectation that the probability of shock termination will be increased by these responses. If expectation is absent, there is little incentive for responses. Fourth, the presence of shock in the escape/avoidance training situation should then arouse the same expectation previously acquired during

* Requests for reprints should be sent to Dr. Jerry W. Thornton, Department of Psychology, Angelo State University, San Angelo, Texas 76901 .

tThe authors wish to thank Gary Studnicka for his assistance in the data collection of Experiment 2 . inescapable shocks. Therefore, the incentive for responding is low.

While several investigations have shown that the generality of the interference transfer extends across subprimate species and that the effect is transituational (Braud, Wepman, \& Russo, 1969; Overmier \& Seligman, 1967; Seligman \& Maier, 1967), Thornton \& Jacobs (1971) have recently extended the species generality to humans. The phenomenon has been replicated with a variety of frequencies, densities, and durations of stress.

One unique feature among studies utilizing the "helplessness" paradigm is that tests of interference transfer have almost exclusively involved motor responses (i.e., latency measures). Seligman (1968), using rats, tested the effects of unpredictable shock in a CER procedure. His results suggested a cognitive deficit (though not referred to as such) which resulted in failure to leverpress due to the unpredictable shock.

The present investigation involved two studies which attempted to measure the effects of prior inescapable/unavoidable shock training with a reaction time (RT) task on subsequent intellectual performance, an area not yet investigated. It was postulated that the administration of an intelligence measure would be mildly stress-provoking and that interference created by prior inescapable/unavoidable trials would be capable of transfer to the intelligence measure.

In accordance with the evidence on motor responding under a state of learned helplessness, it was hypothesized that an avoidable shock (AS) group would respond faster on RT training trials than either the unavoidable-shock (US) or no-shock (NS) groups; Ss in the prior AS group would score higher on the intellectual ability test than Ss in the NS group, due to the increased incentive and decreased interference; and $S s$ in the NS group would have more correct responses than the US Ss, due to the latter's transferring stress interference and having little or no response incentive.

\section{EXPERIMENT 1}

Method

The Ss were 48 introductory psychology volunteers who were assigned randomly to one of three groups according to a prearranged assignment sheet.

The training apparatus, located in three separate rooms, consisted of three identical choice reaction-time (CRT) units, similar to that described by Thornton \& Jacobs (1971).

Shock, generated by a $350-V$ constant-current shock apparatus, was delivered through $1 / 2$-in. silver shock electrodes for $1 \mathrm{sec}$, with shock escape impossible.

Upon entering the laboratory, Ss were placed in three separate rooms and given Form I of the Wonderlic Personnel Test; a 12-min, highly reliable $(98 \%$ within a $30-\mathrm{min}$ test-retest), mental ability test containing items of mathematical and verbal reasoning and perceptual organization.

Following the Wonderlic Form I, each $S$ was moved to the appropriate CRT training task room (Ss were assigned randomly to the three training conditions). After electrodes were attached, Ss were read the experimental instructions.

First, all Ss were informed as to the nature of the CRT task. The AS Ss were informed of the contingency between shock and slow or incorrect responding (i.e., Ss could avoid), and US Ss were informed that they would receive unavoidable shock, unrelated to the CRT task which they were to perform. The US Ss received shock yoked to the AS Ss. The NS Ss received only the CRT task instructions, i.e., no shock. Finally, the AS and US Ss were informed about the shock they would be receiving (i.e., Ss were allowed to adjust their shock level to an unpleasant but not painful level). Following instructions, Ss received 30 CRT trials. The range of the fixed level of shock over all AS and US Ss was .8 to $3.5 \mathrm{~mA}$, with an average level of 2.31 mA. After the 30th trial, Ss were administered Form II of the Wonderlic Test in the training room.

Results and Discussion

Table 1 shows the means and standard deviations of the CRT data and the Wonderlic pre- and posttest.

A one-way ANOVA performed on the CRT training-trial measures revealed a significant difference among 
Means and Standard Deviations for the CRT Training Task* and for the Pre- and Posttest Wonderlict in Experiment 1

\begin{tabular}{|c|c|c|c|c|}
\hline & & \multirow[b]{2}{*}{ CRT } & \multicolumn{2}{|c|}{ Wonderlic } \\
\hline & & & Pretest & Posttest \\
\hline AS & $\begin{array}{l}\text { Mean } \\
\text { SD }\end{array}$ & $\begin{array}{l}.491 \\
.653\end{array}$ & $\begin{array}{r}27.19 \\
4.02\end{array}$ & $\begin{array}{r}28.75 \\
5.04\end{array}$ \\
\hline US & $\begin{array}{l}\text { Mean } \\
\text { SD }\end{array}$ & $\begin{array}{r}.624 \\
1.890\end{array}$ & $\begin{array}{r}22.50 \\
4.89\end{array}$ & $\begin{array}{r}30.94 \\
5.09\end{array}$ \\
\hline NS & $\begin{array}{l}\text { Mean } \\
\text { SD }\end{array}$ & $\begin{array}{r}.681 \\
1.201\end{array}$ & $\begin{array}{r}26.19 \\
6.01\end{array}$ & $\begin{array}{r}26.63 \\
6.08\end{array}$ \\
\hline
\end{tabular}

* Scores represent seconds

tRepresents raw Wonderlic scones (50 possible)
Means and Standard Deviations for the CRT Training Task* and for the Pre- and Posttest Wonderlict in Experiment 2

\begin{tabular}{rlrrr}
\hline & & & \multicolumn{2}{c}{ Wonderlic } \\
\cline { 4 - 5 } & & CRT & Pretest & Posttest \\
\hline \multirow{2}{*}{ AS } & Mean & .430 & 26.67 & 26.67 \\
& SD & .030 & 6.24 & 6.83 \\
\multirow{2}{*}{ US } & Mean & .640 & 26.78 & 33.00 \\
& SD & .110 & 3.12 & 3.06 \\
\multirow{2}{*}{ NS } & Mean & .660 & 26.67 & 26.89 \\
& SD & .100 & 4.16 & 4.65 \\
\hline
\end{tabular}

* Scores represent seconds

tRepresents raw Wonderlic scores (50 possible) groups $(F=3.96$, df $=2 / 45, p<.05)$. A Newman-Keuls multiple-means analysis, conducted on the CRT data to ascertain specific group differences, revealed the following group comparisons: $A S<$ US $=$ NS $(p<.05)$. This finding was in support of the first hypothesis. The AS S's superior RT performance on the CRT training task was postulated to be a result of the increased motivation to respond due to the incentive to avoid shock. Other studies (Jacobs \& Kirk, 1969; Seligman, 1968; Thornton \& Jacobs, 1970 , 1971) have supported the hypothesis that decrements in US S's performance were due to interference resulting from an expectancy of unpredictable unavoidable shock.

The more important measure of the study was the Wonderlic intelligence data revealing the effects of US on cognitive (higher mental) processes. The Wonderlic data (see Table 1) was subjected to a two-way mixed ANOVA which revealed a significant Wonderlic test (pre-pr ittest; a repeated measure) main effect $(F=52.60, \mathrm{df}=1 / 45, \mathrm{p}<.001)$ and $\mathrm{a}$ Shock Contingency by Wonderlic interaction $(F=3.50, \quad d f=2 / 45$, $p<.05)$. Due to the significant interaction, a simple main effects analysis revealed $A S$ and NS to be not significantly different (Fs $<1$, $p>.25$ ) across levels of the Wonderlic test, whereas US significantly differed across pre- and posttest Wonderlic measures $(F=49.90, \quad \mathrm{df}=1 / 45$, $p<.01)$. The second hypothesis concerning US Ss post-Wonderlic decrement was not supported.

The results revealed an interesting phenomenon. The US So scored 38\% more correct responses on the posttest than on the pretest Wonderlic, whereas AS and NS Ss scored only $4 \%$ and $0 \%$ more on the posttest than on the pretest Wonderlic, respectively. The question was raised as to why the US Ss on the average increased their posttest Wonderlic score by $38 \%$ on a test which had a $98 \%$ test-retest reliability, while AS and NS Ss' scores remained relatively unchanged through the posttest.
The second part of the simple main-effects analysis, i.e., across levels of the Wonderlic, suggested a methodological problem. Form I of the Wonderlic differed across AS, US, and NS groups $(F=65.60, d f=3 / 90$, $p<.01$ ), as did Form II Wonderlic $(F=17.93$, df $=3 / 90, \quad p<.01)$. Although randomization procedures were expected to eliminate problems of pretest Wonderlic group differences, such was not the case.

A 2 by 3 ANOVA, conducted to counteract the confounding effects of pretest group differences, resulted in an $F=2.45$, df $=2 / 44, .05>p<.10$. Although this $F$ is not significant at the traditional $\alpha$ level (i.e., <.05), an important trend of differences in the posttest Wonderlic measures was evident. It appeared that the US Ss, after having undergone prior unavoidable/inescapable CRT training, were highly motivated to perform the posttest Wonderlic.

Experiment 2 was performed to eliminate the slight confounding of pretest Wonderlic differences, to utilize a new instructional stress set developed by Thornton \& Jacobs (1971), and to attempt replication of Experiment 1.

\section{EXPERIMENT}

\section{Method}

The Ss were 27 introductory psychology volunteers, who were assigned to the same three groups (i.e., AS, US, and NS) on a matching basis (i.e., matched on pretest Wonderlic scores) so that the groups were homogeneous with regard to pretest raw Wonderlic scores.

The only procedural changes from Experiment 1 were that the pretest Wonderlic in Experiment 2 was given 3 days in advance of the shock trials, and, in place of the traditional "fixed level" of shock instructions, Ss received "variable level" shock instructions (Thornton \& Jacobs, 1971), which involved delivery of shock levels ranging from low to moderate intensity so as to reduce S's predictability of shock intensity. This altered shock procedure was an effort to equate AS and US (yoked shock) shock density, a problem Church (1963) has noted.

Results and Discussion

Table 2 shows the means and standard deviations of the CRT training task data and the pre- and posttest Wonderlic measures.

A one-way ANOVA, performed on the CRT training data to determine differences among groups, revealed a highly significant difference $(F=20.43, \quad$ df $=2 / 24, \quad p<.01)$. A Newman-Keuls, performed to determine specific group differences, resulted in the following mean order: AS $<$ US = NS, which was significant ( $p<.01$ ). The CRT results of Experiment 2 replicated the CRT results of Experiment 1 .

The Wonderlic scores were subjected to a 3 by 2 mixed ANOVA which revealed a significant repeated-measures Wonderlic main effect (i.e., pretest Wonderlic scores were significantly less than posttest Wonderlic scores) $(F=13.28$, $\mathrm{d} f=1 / 24, \quad \mathrm{p}<.01$ ) and a Training-Task Shock Contingency by Wonderlic interaction (i.e., AS, US, and NS Ss differed differentially across pre- and posttest Wonderlic measures) $(F=11.96, \mathrm{df}=2 / 24, \mathrm{p}<.01)$. These results replicate the findings of Experiment 1 in respect to performance on the Wonderlic in the present situation. The Wonderlic main effect revealed that there was a significant increase in scores on posttest over pretest, while the significant Shock Contingency by Wonderlic interaction was crucial in showing that the increase in scores was different for the three groups. Due to the significant interaction, a simple main-effects analysis was performed. Shock contingency (i.e., AS, US, and NS) at pretest Wonderlic was nonsignificant $(F<1)$; thus, the methodological problem of confounded pretest group socres was eliminated in Experiment 2. Shock contingency at posttest Wonderlic was significant $(\mathrm{F}=6.04, \mathrm{df}=2 / 48$, $\mathbf{p}<.01$ ). In order to assess the within-group variability, the Wonderlic variable was examined for each level of 
shock contingency. The US group's pre- and posttest difference was significant $(F=37.15, \quad d f=1 / 24$, $\mathrm{p}<.01)$, which replicated Experiment 1. All other pre/post differences were nonsignificant. Thus, while the AS and NS groups increased their raw Wonderlic score only $0 \%$ and $1 \%$, respectively, from pre- to posttest, the US group increased its score by some $34 \%$ from pre- to posttest.

\section{GENERAL DISCUSSION}

Experiments 1 and 2 provide evidence that intellectual performance following trials of unavoidable/ inescapable shock training is significantly increased. This increase on a test with $98 \%$ test-retest reliability was noted to be significant from groups who received prior training of either avoidable shock or no shock. The following hypotheses were offered to account for the obtained effect.

The transfer of learned-helplessness interference noted in previous reports (Seligman, Maier, \& Solomon, 1969) has been from one motor task to a second motor task, both involving shock (exception: Braud, Wepman, \& Russo, 1969). It was possible that the stress paradigm from Task 1 (CRT) to Task 2 (Wonderlic) in Experiments 1 and 2 was sufficiently different to break the helplessness response set (Seligman, personal communication). In the Wonderlic task, $S$ may have realized that he was in a controllable situation and thus his motivation for success was sufficiently increased to affect his performance. While the US Ss could experience such behavior, AS and NS Ss had no previous training which would alter their subsequent performance.

A second interpretation might involve the Hullian (Hull, 1952) drive concept. Increments in stress and the accompanying increases in drive level, up to a point, may facilitate performance (Broadhurst, 1959), and this could account for a major portion of the increase noted in the US Ss' posttest Wonderlic. Learned-helplessness theory predicts a reduction in incentive and drive for response due to the transfer of interference produced from an unpredictable, uncontrollable situation to a second and different situation which is perceived as being uncontrollable but yet is, in fact, controllable. The $\mathrm{Ss}$ in the present experiments may not have transferred the helplessness interference because they perceived their control on the posttest Wonderlic. Thus, any residual anxiety and stress from the CRT training phase could have acted as a drive increment to facilitate performance. Weiss (1968) has clearly pointed out the strong stress effects of uncontrollable/unpredictable stress, which could well have existed and acted to increase drive in the transfer task.

It would appear that the primary difference in the outcome of the present investigations and those on learned helplessness could be the discriminative cue inherent in the change of tasks in the two experiments described herein but absent in the learned-helplessness studies. A stimulus change (e.g., generalization decrement theory; Kimble, 1961) possibly acted to make the test phase (i.e., Wonderlic) distinctively different from CRT training trials, so that the response set of interference was eliminated because it did not transfer.

The transituational nature of leamed helplessness, evidenced above in animal studies, may not be applicable to a transfer from motor to cognitive (intellectual) processes. The $S s$ received the same exact learned-helplessness acquisition as did Thornton \& Jacob's (1971) Ss. We may, thus, infer that they initiated the transfer with sufficient interference to affect motor responding, but either the differential cue signaled controllability ("alleviated helplessness") or the interference was not of sufficient strength to affect a cognitive task. In either case, the acquired learned-helplessness state was nonfunctional at the onset of the test phase under the present conditions.

\section{REFER ENCES}

BRAUD, W., WEPMAN, B., \& RUSSO, D. Task and species, generality of the "helplessness", phenomenon. Psychonomic Science, 1969, 16, 154-155.

BROADHURST, $P$. L. The interaction of task difficulty and motivation: The Yerkes-Dodson law revived. Acta Psy chology, 1959, 16, 321-338.

CHURCH, R. M. The varied effects of punishment of behavior. Psychological Review, 1963, 70, 369-402.

HULL, C. L. A behavior system. New Haven: Yale University Press, 1952.

JACOBS, P. D., \& KIRK, R. E. The effects of task related stress on human performance of a two-component monitoring task. Perceptual \& Motor Skills, 1969, 29, 815-823.

KIMBLE, G. A. Hilgard and Marquis" conditioning and learning. New Yodk: Appleton-Century-Crofts, 1961 .

OVERMIER, J. B., \& SELIGMAN, M, E.P. Effects of inescapable shock upon subsequent escape and avoidance responding. Joumal of Comparative \& Physiological Psychology, 1967, 63 . 28-33.

SELIGMAN, M. E. P. Chronic fear produced by unpredictable electric shock. Journal of Comparative \& Physiological Psychology, 1968, 66, 402-411.

SELIGMAN, M. E. P., \& MAIER, S. F. Failure to escape traumatic shock. Journal of Experimental Psychology, $1967,74,1-9$.

SELIGMAN, M. E. P:, MAIER, S. F., \& SOLOMAN, R. L. Unpredictable and uncontrollable aversive events. In F.R. Brush (Ed.), Aversive conditioning and learning. New York: Academic Press, 1969.

THORNTON, J. W.. \& JACOBS, P, D. Analysis of task difficulty under varying conditions of induced stress. Perceptual \& Motor Skills, 1970, 31, 343-348.

THORNTON, J. W., \& JACOBS, P. D. Learned helplessness in human Ss. Journal of Experimental Psychology, $1971,87,367-372$.

WIESS, J. M. Effects of coping responses on stress. Journal of Comparative \& Physiological Psychology, 1968, 65.
251-260. 